\title{
M. Foucault: poder, perspectiva y verdad en Edipo Rey de Sófocles
}

\author{
M. Foucault: Power, Perspective and Truth in Oedipus Rex \\ by Sophocles
}

JOSÉ MANUEL PANEA MÁRQUEZ*

\begin{abstract}
Resumen: Nos proponemos en este artículo analizar la lectura foucaultiana del Edipo Rey. Foucault se centra fundamentalmente en la relación entre saber y poder. Su lectura nos ofrece una interesante concepción simbólica de la verdad, cuyo desvelamiento seguiría las pautas de lo que Foucault llama "ley de las mitades". El modo y los tiempos en que aparecen los diferentes fragmentos de la verdad serán el centro de gravedad de su interpretación, esencialmente política. Proponemos, no obstante, ir un poco más allá de tan sugerente enfoque, reflexionando sobre las diferentes voces y perspectivas del texto, preguntándonos por la voz del poeta, su posible significado filosófico, no sólo para los ciudadanos de su tiempo, sino también para nosotros.
\end{abstract}

Palabras clave: Sófocles, Foucault, Edipo Rey, poder, perspectiva, verdad.

\begin{abstract}
The paper is intended as an assessment of Foucault's reading of Oedipus Rex. Foucault basically focuses on the relationship between knowledge and power. His interpretation provides us with a symbolic conception of truth, the unveiling of which would follow the guidelines of what Foucault labels "the law of halves". Both the manner and the times, in which the different fragments of truth appear, will be the centre of gravity of his essentially political interpretation. It is proposed, however, to take a step further from such an inviting view, in order to reflect on the different voices and perspectives of the text, and delve into the poet's voice and its possible philosophical meaning, beyond the mere political scope of the work, not only for the citizens of Sophocles' time, but for all of us.
\end{abstract}

Keywords: Sophocles, Foucault, Oedipus Rex, power, perspective, truth.

\section{Introducción}

Todo lenguaje es un alfabeto de símbolos cuyo ejercicio presupone un pasado que los interlocutores comparten. J. L. Borges, El Aleph.

Recibido: 19/05/2018. Aceptado: 30/06/2018.

* Profesor de Filosofía Moral y Política en la Facultad de Filosofía (Universidad de Sevilla). Sus líneas actuales de investigación giran en torno a la moral y la política, a partir de la proximidad entre literatura y filosofía. Entre sus recientes trabajos podrían citarse: "El papel de las emociones en la esfera pública: la propuesta de M.C. Nussbaum", en Recerca: Revista de Pensament i Anàlisi (2018), y “José Luis Aranguren: Cervantes y el héroe interior", en Isegoría (2017).Correo electrónico: jmpanea@us.es 
Si nos preguntamos hoy por el interés, más allá del meramente erudito, de un autor como Sófocles, y, en particular, de una obra tan comentada como Edipo Rey, una posible respuesta sería que encontramos en ella no sólo una pieza dramática magistral, de insuperable belleza, y una trama perfectamente enlazada, con una fuerza expresiva sin parangón, sino también de una extraordinaria virtualidad filosófica ${ }^{1}$. En esta línea, proponemos tomar como punto de partida las reflexiones que, en diferentes momentos de su trayectoria intelectual, hiciera Michel Foucault sobre dicho drama ${ }^{2}$. La lectura foucaultiana se articula en torno a la problemática de la verdad y del poder. En una indagación filosófica en torno a puntos de vista, tal como ahora nos ocupa, su interpretación propicia no sólo una original mirada política sobre el texto, sino que nos brindará una magnífica oportunidad para repensarlo filosóficamente, y preguntarnos, a partir del análisis de las distintas perspectivas que encarnan las diferentes voces del drama, si la tragedia ha muerto (Steiner, 2012), o en cambio tiene mucho que decirnos también hoy a nosotros (Williams, 2011, 39-44; Lariguet, 2014).

\section{M. Foucault: poder y verdad en Edipo Rey}

Lo que interesa a Foucault es el tipo de relación entre saber y poder, entre poder político y conocimiento que hay en Edipo. La obra obedece exactamente a las prácticas judiciales griegas de la época (Foucault, 2003, 39-40). En la Grecia antigua, la investigación de la verdad tenía que ver con el juramento y su aceptación. Y aunque hay algunas reminiscencias en la obra (como cuando Creonte jura delante de Yocasta no haber conspirado contra Edipo; o enviar al exilio al asesino de Layo) el mecanismo de investigación de la verdad obedece a una indagación que Foucault llamará ley de las mitades: Edipo manda consultar al dios de Delfos, Apolo, y su respuesta se da en dos partes; sobre Tebas cae una maldición, pero hay que saber cuál es la causa: un asesinato, y Apolo sólo contestará diciendo una parte: el asesinado es Layo, faltando saber la otra mitad, quién lo hizo (Foucault, 2003, 42). Como no se puede forzar la voluntad de los dioses, hay que seguir preguntando. La sombra mortal de Apolo (dios de la luz) es el ciego adivino Tiresias. Se le interrogará y acusará a Edipo de haber matado a Layo. Desde la segunda escena, nos dirá Foucault, todo está dicho: maldición, asesinato; quién fue muerto, quién mató. Apolo anunció que pesaba una maldición sobre Tebas, y que había que expiar la falta. Foucault insistirá en que tenemos toda la verdad pero en forma prescriptiva y profética, característica del oráculo y del adivino. A pesar de que es completa y total, según el análisis foucaultiano, la verdad oracular sólo se refiere al futuro -lo que seguirá ocurriendo si aquella no se expía, lo que sucederá si se expía-; faltándole el pasado y el presente, reproduciéndose también un juego de mitades relativo al tiempo (Foucault, 2003, 44). Pero como veremos, sucesivamente irán hablando los distintos personajes, las distintas voces, que completarán el juego de mitades (Apolo y Tiresias, verdad divina; Yocasta y Edipo, verdad regia; los dos pastores, verdad humana): "Tenemos entonces seis poseedores de la verdad que se agrupan de a dos para hacer un juego de mitades que es el juego de las seis mitades (...) En suma, en cada uno de los tres grupos de dos personas diferentes, poseen cada una uno de los fragmentos

1 Aristóteles destacó la superioridad filosófica de la poesía sobre la historia (Poética, 1451b 4-8). Respecto a la dimensión filosófica de la tragedia, Kitto (1968), 140-141; Vernant (1987), 7-27; Nussbaum (1995), 27-50; Trueba (2004), 91-96.

2 Una revisión completa la encontramos en Incerti (2018). 
de la verdad" (Foucault, 2016, 42-43). La integración de los puntos de vista divino y humano resulta inexcusable, si aspiramos a comprender la verdad completa, dada su naturaleza simbólica, pues el procedimiento de búsqueda obedece al mecanismo del símbolo ( $\sigma u ́ \mu \beta o \lambda o v)$ : Edipo, rodeado de intolerables duplicidades, encarnará una verdad que se prueba sólo cuando se reúnen las mitades (Foucault, 2015, 231-232).

En efecto, volviendo al crimen de Layo, es preciso determinar quién lo mató. Sabemos una mitad: que Layo fue muerto en una encrucijada de tres caminos; pero falta la otra: saber si fue obra de uno o de varios. Y cuando se descubra que Edipo es el causante de la muerte de Layo, faltará la otra mitad: determinar si era su hijo. Y para completarla será todavía necesario el acoplamiento de dos testimonios diferentes: el del esclavo que viene de Corinto, anunciando a Edipo la muerte de Pólibo, del que le informará que no era su verdadero padre; y el del esclavo escondido en las profundidades del Citerón, el pastor que durante años habría guardado la verdad: que recibió un niño de manos de Yocasta, para acabar con su vida, y que por compasión (éleos) lo entregó al mensajero de Corinto. Así, el juego de mitades irá completándose sucesivamente (Foucault, 2003, 44-46), con arreglo a una técnica precisa:

Esta forma del Edipo de Sófocles, realmente impresionante, no es sólo una forma retórica, es al mismo tiempo religiosa y política. Consiste en la famosa técnica del

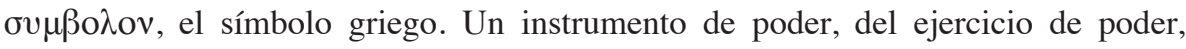
que permite a alguien que guarda un secreto o un poder romper en dos partes un objeto cualquiera- de cerámica, por ejemplo-, guardar una de ellas y confiar la otra a alguien que debe llevar el mensaje o dar prueba de su autenticidad. La coincidencia o ajuste de estas dos mitades permitirá reconocer la autenticidad del mensaje, esto es, la continuidad del poder que se ejerce. El poder se manifiesta, completa su ciclo y mantiene su unidad, gracias a este juego de pequeños fragmentos separados unos de otros, de un mismo conjunto, de un objeto único, cuya configuración general es la forma manifiesta del poder. La historia de Edipo es la fragmentación de esta obra, cuya posesión integral y reunificada autentifica la detención del poder y las órdenes dadas por él. Los mensajes, los mensajeros que envía y que deben regresar, justificarán su vinculación con el poder porque cada uno de ellos posee un fragmento de la pieza que se combina perfectamente con los demás. Los griegos llaman a esta técnica

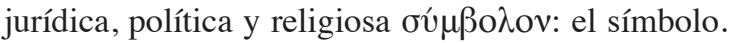

La historia de Edipo, tal como aparece representada en la tragedia de Sófocles, obedece a este бú $\mu$ ßòov: no es una forma retórica, sino más bien religiosa, política, casi mágica del ejercicio del poder. (Foucault, 2003, 46-47).

Así pues, se producirán varios ensamblajes necesarios en la obra: el del dios Apolo y el del adivino Tiresias (nivel de la profecía o de los dioses); el de Edipo y Yocasta (nivel de los reyes); el del mensajero de Corinto y el pastor de Tebas (nivel de los esclavos y servidores). Lo interesante, nos dirá Foucault, es que las profecías se confirman; que la forma de la profecía hacia el futuro, coincide con el pasado y con el presente; que la palabra de los dioses se armoniza con la de los hombres, reyes y sirvientes (Foucault, 2016, 76). La forma en la que aparece la verdad completa no es la profecía, sino el testimonio de los pastores, que encaja a la perfección con la verdad profética: la mirada de los dioses coincide con la 
mirada retrospectiva de aquéllos, desplazándose el brillo o luz de la verdad, de lo profético y divino, a lo empírico, cotidiano y humano. $\mathrm{Y}$ al final la verdad es una, vista y expresada de distinto modo: "Entre los pastores y los dioses hay una correspondencia: dicen lo mismo, ven la misma cosa, pero no con el mismo lenguaje y tampoco con los mismos ojos. Durante toda la tragedia vemos una única verdad que se presenta y formula de dos maneras diferentes, con otras palabras, en otro discurso, con otra mirada. Sin embargo, estas miradas se corresponden. Los pastores responden exactamente a los dioses; podríamos decir incluso que los simbolizan. En el fondo, lo que los pastores dicen es aquello que los dioses ya habían dicho, sólo que lo hacen de otra forma." (Foucault, 2003, 49).

Así se entiende la concepción simbólica de la verdad que hay en Edipo. Edipo, cuya etimología -nos recuerda Foucault- se emparenta con haber visto y con saber, es aquel que sabía demasiado, como luego se descubrirá, aquel que unía saber y poder de una manera condenable (Foucault, 2003, 50). Y es aquí donde Foucault nos propondrá una lectura esencialmente política del drama: el título de la obra, Edipo rey (tú @avvos), nos remite al tema central, el poder de Edipo, que se sabe amenazado: "En suma, el personaje central del Edipo Rey de Sófocles no invoca en ningún momento su inocencia o la excusa de haber actuado de modo inconsciente. (...) A Edipo no le asusta la idea de que podría haber matado a su padre o al rey, teme solamente perder su propio poder." (Foucault, 2003, 51).

En su lectura política de la obra, Foucault insiste en que Edipo es el ánthropos týrannos, hecho a sí mismo, que obtiene el poder tras sufrir una serie de peripecias, y de haber realizado una proeza, que lo legitima ante los ciudadanos (Knox, 1957, 107), y de aquí que sea especialmente sensible ante la posibilidad de perderlo (Foucault, 2003, 53-54). Pero Sófocles también nos muestra su lado negativo: al conversar con Creonte, su celo por la ciudad se identifica con su celo por preservar el poder, en consonancia con los tiranos griegos, que se consideraban salvadores y dueños de la pólis, hasta el punto de que las leyes quedaban a merced de su voluntad, fiel al modelo histórico del týrannos (Foucault, 2016, 70-71). Sófocles estaría cuestionando la concepción tiránica del poder, incompatible con la pólis democrática (Orsi, 2007, 304-305; Carrasco, 2009, 132-139). Sin embargo, lo decisivo será no sólo el poder, sino el hecho de estar en posesión de un saber superior: Edipo descifró el enigma de la Esfinge (Foucault, 2003, 54-56).

Ahora bien, ¿qué tipo de saber es el de Edipo? Para caracterizarlo, Foucault insistirá en que,

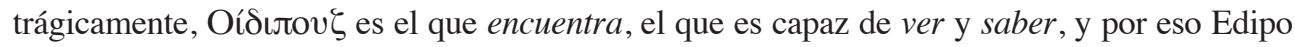
es el hombre que ve, el hombre de la mirada, y lo será hasta el final, hasta cegarse él mismo. Y el error trágico de Edipo (hamartía), apuntará Foucault, es haber postergado el testimonio. El saber de Edipo es un saber solitario; el saber del hombre que quiere descubrirlo todo con sus propios ojos, sin apoyos en lo que se dice o se oye; el saber autocrático del tirano, que se cree que por sí solo es capaz de gobernar la ciudad (Laleff, 2018), y de aquí que se considere el piloto, el conductor que en la proa del navío abre los ojos para ver, el único guía. Pero es en este abrir los ojos sobre lo que está ocurriendo cuando se topará con la barrera infranqueable

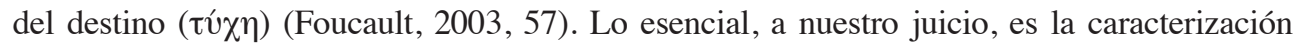
del poder y del saber autocrático de Edipo, que finalmente resultará deficitario (Monge, 2015, 37-40): "Quisiera mostrar que, en realidad, Edipo representa en la obra de Sófocles un cierto tipo de lo que yo llamaría saber-y-poder, poder-y-saber. Y porque ejerce un poder tiránico y solitario -desviado tanto del oráculo de los dioses que no quiere oír como de lo que dice y 
quiere el pueblo- en su afán de poder y saber, de gobernar descubriendo por sí solo, encuentra en última instancia los testimonios de quienes vieron”. (Foucault, 2003, 58).

Lo interesante, nos parece a nosotros, es que el infalible y deslumbrante saber del tirano quedará desmitificado, puesto en cuestión. Aquel que parecía saberlo todo, porque descifró el Enigma, ignoraba, en cambio, lo fundamental: que es él, en última instancia, el desencadenante de todo el mal, al ser él mismo el asesino de Layo. Tal es la ironía trágica de la que Sófocles se vale constantemente en la obra, y cuyo eje central será la finitud del conocimiento, algo que queda patente en el contraste dioses-espectadores, por un lado, y Edipo, por otro, consiguiendo con este desdoblamiento de planos un interesante golpe de efecto crítico (Orsi, 2007, 256-264). El todopoderoso saber autocrático del tirano quedará desenmascarado en su precariedad por el testimonio de los pastores, que encajará a la perfección con el saber de las profecías y oráculos. El saber autocrático es superado por el saber oracular, divino (Tiresias) y por el testimonial, humano, intersubjetivamente reconstruido (los pastores), que encajan. Y además, añadirá Foucault, al demostrarse la precariedad, la insuficiencia del saber de Edipo, éste no sólo será señalado como culpable, sino que quedará deslegitimado para seguir ejerciendo el poder (Laleff, 2018, 73-80). Edipo Rey subrayará el desgarro entre saber y poder, la irreductibilidad entre la práctica del saber y la práctica del poder (Derrida, 2014, 69), cuya fractura será más tarde hilo vertebrador de la filosofía platónica (Foucault, 2003, 58-59).

\section{Otras voces, otras perspectivas}

Dejemos, para más tarde retomarla, la sugerente lectura foucaultiana. Adentrémonos en el texto mismo para rastrear la polifonía de voces que entretejen el drama, frente a la voz unitaria de Edipo (Orsi, 2007, 57; 60-69) ${ }^{3}$. La primera imagen será la de un grupo de jóvenes y de ancianos, sentados en las gradas del altar, en actitud suplicante, portando ramas de olivo, y junto a ellos, el sacerdote de Zeus y dos ayudantes. La ciudad está llena de incienso, cantos de súplica y gemidos. Edipo se dirige al más anciano de todos, y dice de sí mismo ser Edipo, famoso entre todos (v. 9), y quiere saber a qué obedece todo aquello, si al temor o al ruego; les muestra su voluntad de ayuda, y también su compasión (vv. 10-14). El sacerdote de Zeus le anuncia que todo el pueblo, jóvenes y ancianos, están en actitud suplicante, y le informa de la peste (míasma) que asola la ciudad, y cómo esperan su ayuda, pues él, probablemente guiado por algún dios, supo una vez librarlos de la sanguinaria Esfinge, enviada por Hera contra Tebas, como castigo del crimen de Layo (rapto y violación) contra Crisipo, hijo de Pélope. Es la voz del sacerdote, en nombre de la ciudad, quien suplica a Edipo, el más sabio entre todos (v.40), para que les proporcione alguna ayuda. Apelan a su saber, a su experiencia (v.45). Se dice de él que es el mejor de los mortales y el salvador de la ciudad (v.46). Edipo escucha con compasión, y admite su dolor, "por la ciudad, y por mí y por ti" (v. 65). Y les narra cómo lleva ya vertidas muchas lágrimas, y cómo no ha encontrado nada mejor que interrogar al dios, enviando a su cuñado Creonte a la morada Pítica de Febo, a

3 Sobre la importancia en Sófocles de interpretaciones y sentidos colectivos, significados múltiples y puntos de vista difícilmente compatibles, cuestionando el saber autocrático de Edipo, el intelectualismo sofista y la tradición de los mitos, consciente de la ambigüedad fundamental del ser humano, véase Rocco (2000), 77-85. 
fin de saber qué hacer para liberar a la ciudad del dolor, con voluntad de cumplirlo, pues sería malvado no acatar lo que el dios manifieste (vv. 65-75).

Creonte regresa de Delfos contento, pero quiere cerciorarse de si la respuesta del dios debe exponerla en privado o públicamente ${ }^{4}$. El sufrimiento es de todos, dirá Edipo, luego de todos debe ser conocida (vv. 94-95). Se nos dice, entonces, que la región está mancillada por un antiguo crimen -la muerte de Layo-, que debe ser vengado. Creonte expondrá cómo Layo salió a consultar al oráculo; y que sólo uno de los acompañantes sobrevivió, quien afirmaría que fueron varios ladrones quienes le dieron muerte. La mentira, en su día, del mensajero se explica, tal vez, para disculpar su despavorida huida. Edipo no entiende cómo ha pasado tanto tiempo sin esclarecerse el asunto, a lo que Creonte alegará que la Esfinge reclamaba toda su atención. Edipo se muestra decidido a clarificarlo, y ello porque el que fuera asesino de aquél tal vez pudiera querer ejercer contra él violencia semejante (vv. 135-140). Lo que al principio era sólo compasión cede ahora su sitio a la propia conservación de la vida y del poder. Justo aquí arrancará la lectura foucaultiana de Edipo como una tragedia política. Edipo invocará la ayuda de la divinidad, para indagar el tema hasta el final (v. 145).

El Coro expresará su temor, implorando a Zeus, a Atenea, a Ártemis, protectora del país, y a Apolo, como preservadores de la muerte. Ahora toda la ciudad escucha la voz que nace del dolor de la tierra infecta, de los ríos, de las parturientas, de las esposas y ancianas que pierden a maridos e hijos (vv. 155-215). Y Edipo pronunciará un largo discurso, ordenando que quien sepa algo sobre la muerte de Layo lo revele sin temor a castigo, exhortando a todos para que no lo encubran; prometiendo cumplir su palabra, aunque el culpable se hallara en palacio (vv. 215-250), haciéndolo "por mí mismo, por el dios, y por este país tan consumido en medio de esterilidad y desamparo de los dioses. Pues, aunque la acción que llevamos a cabo no hubiese sido promovida por un dios, no sería natural que vosotros la dejarais sin expiación, sino que debíais hacer averiguaciones por haber perecido un hombre excelente" (v. 254- 259). Sin duda, llama la atención cómo ahora Edipo esgrime una razón de excelencia política, y que incluso afirme que están desamparados de los dioses, lo que apunta a él como posible y único salvador. Y parece entonces evidente que el motivo que sostiene la búsqueda tiene que ver más con la razón alegada por Foucault, que con la compasión. Si avanzamos en el pasaje, Edipo nos recuerda su posición de rey, suplantando a Layo, y cómo piensa defenderlo hasta el final, y capturar al asesino (vv. 260-265). Y el Corifeo asevera, ofendido, que ninguno de ellos ha sido responsable de su muerte, y que si Febo no lo ha dicho, podrían conocer la respuesta exacta si preguntan a Tiresias (vv. 285-286). Por tanto, estamos ante la voz de la ciudad, que interroga, pero que sabe también dónde hallar la respuesta, contrastando con el procedimiento, cargado de vacilación, que inició Edipo. Y no pasemos por alto que la iniciativa de consultar al oráculo nació como sugerencia del propio Creonte (v. 555). Por otra parte, el Corifeo no tiene dudas en referirse al adivino como el que lo dejará todo al descubierto, por ser el único de los mortales en quien la verdad es innata, ya que le ha sido revelada por los dioses. Edipo, en cambio, mencionará las artes adivinatorias de Tiresias, de las que no parece esperar gran cosa, y no le ordena, sino que más bien le anima a que preste sus servicios (vv. 295-315). Pero el

4 Por ello, la política se inscribe en el secreto, y ejerce una dominación que se pone en cuestión en la obra (Laleff, 2018, 61-83). 
abatimiento de Tiresias, y la voluntad de marcharse sin hablar, no presagian nada bueno. Y tal vez la angustiosa renuencia del adivino a confesar lo que sabe -pues sólo cederá ante la amenaza de muerte- es lo que alertará a Edipo, al que Tiresias culpará de ser "el azote impuro de esta tierra" (v. 355). Al oírlo, Edipo le acusará de mentir, de estar "ciego de los oídos, de la mente, y de la vista" (v. 370), desacreditando su saber, y reprochándole vivir en una noche continua (v. 375), acusándole de haber tramado con Creonte una maniobra para hacerse con el poder (v. 535). Edipo desconfiará absolutamente del escrutador de aves y de sus malas artes, cuyo inútil saber no pudo salvar a la ciudad de la Esfinge (vv. 380400). El Corifeo achacará las palabras de uno y otro a la cólera (v. 405). Pero sin duda, el momento más álgido del drama será el diálogo, de perspectivas contrapuestas, entre Edipo y Tiresias, descubriéndole todo lo que necesita saber, aunque aquél no lo admita (vv. 405460). Y el Coro expresará su perturbación y perplejidad (v. 485), suspendiendo el juicio, contraponiendo sabiduría a sabiduría (v. 505), porque si Tiresias es un sabio adivino, no menos sabio es Edipo, que descifró el Enigma.

Y reaparecerá Creonte, defendiéndose de la imputación de complot vertida por Edipo, que el Corifeo atribuirá significativamente a la cólera (vv. 515-530). Edipo lo acusará de asesino y de usurpador manifiesto de su soberanía (v. 535); Creonte le recordará que está casado con su hermana, y que a él nada le falta, viviendo mejor que si gobernara, libre de los temores y cargas del poder (vv. 550-600); y le anima a ir él mismo a Delfos, y comprobar si ha anunciado o no fielmente la respuesta del oráculo (v. 605), pues sus intenciones han sido honestas (v. 615).

Sorprende la iracunda actitud que Edipo ha demostrado en todo el largo diálogo, hasta desear incluso que muera Creonte (v. 624). Se suscita, además, el problema de la obediencia al poder de Edipo: Creonte alegará la falta de cordura de éste, y que aunque insista en que hay que obedecer al que detenta el poder, expresará Creonte su negativa, si lo ejerce mal (vv. 625-630). Yocasta les reprochará mantener una irreflexiva discusión (v. 635). Pero Creonte, tras informarle de las acusaciones de Edipo, y de las penas previstas contra su persona -el destierro o la muerte- jurará y propondrá morir maldito, si fuera verdad lo que dice éste; y aquí Yocasta le rogará que dé crédito al juramento. Pero se hará patente que Edipo no tiene, en este momento, ninguna voluntad de verdad, sino sólo de conservar el poder, para lo cual necesita hacer válida la acusación contra Creonte. Por eso le dirá al Coro que lo que ellos pretenden -que tome por verdad el juramento de Creonte- significa buscar su ruina o su destierro (vv. 640-660). Edipo, cegado por el odio, como le reprochará Creonte, no puede entender nada (vv. 660-675). Y es aquí donde Yocasta expresará su deseo de saber qué sucede (v. 680). Edipo referirá, nuevamente la supuesta conspiración de Creonte, al imputarle el asesinato de Layo (v.700). Yocasta, al confirmar que dicha información procede de Tiresias, la cuestionará, negándole toda capacidad para la adivinación, por ser un mortal más (v. 710), y narrará cómo una vez le llegó a Layo un oráculo, según el cual moriría a manos del hijo de ambos; pero a Layo lo mataron unos salteadores, en una encrucijada de tres caminos; además, con sólo tres días, Layo amarró al niño por los pies y ordenó abandonarlo en un monte infranqueable; de manera que no hay que prestar atención a los oráculos, pues los dioses, cuando lo necesitan, hablan sin rodeos (vv. 710-725).

Con su discurso, Yocasta pretendía tranquilizar a ambos, zanjando el asunto. Pero lejos de calmarlo, las palabras de Yocasta han sembrado la agitación en Edipo. Incluso Creonte 
hará notar que aquél ha dado un completo giro en su actitud (v. 725-730), porque observamos ahora que el interés por la verdad pasa a primer plano, interrogando a Yocasta (vv. 730-860), sin aludirse a la cuestión que era antes prioritaria, la preservación de su propio poder.

Desmenuzando el largo diálogo, se ofrecen datos: el crimen sucedió poco antes de aparecer él en la ciudad; afirmará que el aspecto de Layo, y que su figura "no era muy diferente de la tuya" (vv. 740-745), lo que hará sospechar a Edipo si Tiresias no estaría en lo cierto; que eran varios los acompañantes de Layo, y que sólo uno escapó con vida, y cómo ese superviviente, al llegar Edipo, quiso que Yocasta lo enviara al campo, lo más alejado posible de la ciudad. La información le produce una zozobra tal que reclama la presencia del pastor (vv. 755-775). Y será ahora cuando Edipo inicie su relato de los hechos: cómo creyó ser hijo de Pólibo y Mérope, reyes de Corinto; cómo en un banquete un borracho le espetó que él era un falso hijo de su padre; cómo sus padres negaron tal injuria, aunque a él le había calado hondo (v. 785); cómo, en secreto, marchó a Delfos, y allí se le anunció que se uniría a su madre, que traería al mundo una descendencia insoportable de ver, y que sería el asesino del padre que lo engendró (vv. 790-795); y cómo, desde entonces, siguiendo la posición de las estrellas, se alejó todo lo posible de Corinto, hasta que llegó al cruce de tres caminos, del que lo habían arrojado fuera, y que allí se originó la pelea, en la que violentamente mató a todos (vv. 800-810). Y en ese momento, teme haber dado muerte al rey (que aún no sospecha que pueda ser su padre), y haber mancillado su lecho (v. 820). El Corifeo aún alberga alguna esperanza de que el pastor lo desmienta. Yocasta tratará de calmarlo, porque, según Loxias, a Layo lo mataría un hijo suyo, y aquel niño murió muy pronto. Pero Edipo necesita la confirmación del pastor; de aquel que, como subrayó Foucault, había sido testigo directo de los hechos (vv. 795-860). La ley de las mitades está a punto de cerrarse.

Y será ahora cuando, a nuestro juicio, asistamos a una voz fundamental en el drama, la del Coro -tal vez la del propio Sófocles-, encarnación de la ciudad (Errandonea, 1970; Gardiner, 1987), cantando a la pureza de las palabras y de las acciones que brotan del Olimpo, a diferencia de las que nacen de naturaleza mortal (Estrofa $1^{\mathrm{a}}$ ); o lamentando la insolencia del tirano (Antístrofa $1^{\mathrm{a}}$ ), que lo precipita en un abismo de fatalidad (vv. 875-880); o condenando la soberbia humana (Estrofa $2^{a}$ ): "Si alguien se comporta orgullosamente en acciones o de palabra, sin sentir temor de la Justicia, ni respeto ante las moradas de los dioses, ¡ojalá le alcance un funesto destino por causa de su infortunada arrogancia!" (vv. 885-890); advirtiendo a los espectadores ${ }^{5}$ (Antístrofa 2) a , a propósito de lo que están viendo, de la actitud con la que Yocasta, sin la menor sombra de duda, ha pretendido disipar los temores de Edipo, afirmando que los oráculos nada podrían contra la voluntad decidida de los dos reyes, que ordenaron el infanticidio del heredero, precisamente para esquivarlos.

Pero detengámonos en la queja del Coro: "Se diluyen los antiguos oráculos acerca de Layo, extinguiéndose, y Apolo no se manifiesta, en modo alguno, con honores, y los asuntos divinos se pierden". (vv. 905-910). Y es precisamente aquí donde queremos llegar: ¿no será esta voz también la de Sófocles? Una lectura política tan perspicaz como la de Foucault, ¿no cabrá insertarla en una reflexión de más alcance? ¿No es la alusión a los

5 Sobre el papel de la tragedia, no sólo como kátharsis (liberación, descarga), sino como dynamía poética capaz de afectar la inteligencia y sensibilidad de los espectadores (Aristóteles, Poética, 1450a 30-31), convirtiéndose en un espejo en el que mirarnos a nosotros mismos y aprender a mirar a los otros, Trueba (2004), 43-63. 
reyes -padres- y al tirano Edipo una referencia ejemplar, precisamente para provocar una reflexión sobre sus conductas, y no sólo de carácter político? ¿No se estará llamando la atención precisamente sobre la imposibilidad de que la humana voluntad, por poderosa que sea, pueda tener todo bajo control? Y precisamente por ello, justo al finalizar el Coro su protesta, dirá Yocasta: "se me ha ocurrido la idea de acercarme a los templos de los dioses con estas coronas y ofrendas de incienso en las manos" (v. 912). Llama la atención la actitud de Yocasta, que en ningún momento ha demostrado una sincera preocupación religiosa, y que ahora se refiere a su ofrenda a Apolo como una ocurrencia, en segunda opción, diríamos, ya que, según confesión propia, no ha conseguido tranquilizar a Edipo, y todos necesitan alguna liberación purificadora, puesto que ahora sienten ansiedad al ver asustado al que es como el piloto de la nave (vv. 910-920). Pero Yocasta, ¿no estaría mostrando una concepción decididamente oportunista en relación a lo divino? Cuando llega el Mensajero de Corinto, informando de la muerte de Pólibo, y de que quieren hacer rey a Edipo (v. 940), se evidencia la actitud altanera de Yocasta con los oráculos, a los que no les concede crédito, pues queda confirmado que Edipo no ha matado a su padre:

YOCASTA.- Sirvienta, ¿no irás rápidamente a decirle esto al amo? ¡Oh, oráculos de los dioses! ¿Dónde estáis? Edipo huyó hace tiempo por el temor de matar a este hombre y, ahora, él ha muerto por el azar y no a manos de aquel. (vv. 945-950).

Este pasaje se nos antoja esencial, pues vuelve a remarcar-irónicamente- la idea de fondo: los asuntos divinos se pierden, pues parece que todo ha sido obra del azar. Y Edipo secunda esta misma actitud, cuando el Mensajero le anuncia la muerte de su padre, debido a la enfermedad y a sus muchos años, haciéndose patente el nulo valor que ambos otorgan a los oráculos, y su convicción de que la fortuna ha suplantado cualquier posible intervención divina:

EDIPO.- ¡Ah, ah! ¿Por qué, oh mujer, habría uno de tener en cuenta el altar vaticinador de Pitón o los pájaros que claman en el cielo, según cuyos indicios tenía yo que dar muerte a mi propio padre? (...) En cualquier caso, Pólibo yace en el Hades y se ha llevado consigo los oráculos presentes, que no tienen ya ningún valor.

YocAsta.- ¿No te lo decía yo desde antes?

EDIPO.- Lo decías, pero yo me dejaba guiar por el miedo.

YocASTA.- Ahora no tomes en consideración ya ninguno de ellos.

EDIPO-- ¿Y cómo no voy a temer al lecho de mi madre?

YocAsta.- Y ¿qué podría temer un hombre para quien los imperativos de la fortuna son los que le pueden dominar, y no existe previsión clara de nada? Lo más seguro es vivir al azar, según cada uno pueda. Tú no sientas temor ante el matrimonio con tu madre, pues muchos son los mortales que antes se unieron también a su madre en sueños. Aquel para quien esto nada supone más fácilmente lleva la vida. (vv. 964-973).

Yocasta acciona el mecanismo de la ironía trágica, exhortándole a entregarse al azar y a no temer por ello, pues gran ayuda es ya la muerte de su padre, algo que Edipo admitirá, sin el más mínimo atisbo de tristeza por su pérdida (vv. 985-990). Pero todo se complicará cuando el Mensajero pida una aclaración a Edipo, quien explicará que Loxias afirmó que 
él mataría a su padre y se uniría a su propia madre, y que por eso teme regresar a Corinto. Entonces, el anciano Mensajero le dirá que pierda cuidado, pues no era hijo de Pólibo, narrando cómo lo encontró en los desfiladeros selvosos del Citerón, siendo en aquel momento su salvador (v. 1030); detallándole que tenía perforados sus tobillos -de ahí su nombre-, y que un pastor de Layo se lo entregó. Y Edipo acrecienta entonces su deseo de verlo e interrogarlo. Será Yocasta la que, repentinamente, le implore que no investigue más (v. 1060). Y augurando lo peor, exclamará: “¡Oh, desventurado! ¡Que nunca llegues a saber quién eres!” (v. 1069). Y Yocasta se retira apresurada.

Estamos en el momento decisivo de la obra, cuando haga acto de presencia aquél en quien Edipo tenía toda su esperanza (vv. 835-837), pero que será el detonante de su total desesperación, al llegar al punto álgido del conocimiento de sí mismo ${ }^{6}$. La foucaultiana ley de las mitades está a punto de concluir su proceso. El Corifeo confirma la presencia del pastor más fiel de Layo -aunque hemos visto cómo por compasión desobedeció su infanticida orden-, y el Mensajero lo corrobora. Y aunque aquél se resista todo el tiempo a responder, Edipo, amenazándolo de muerte, lo obligará a confesarlo todo: que Yocasta le entregó al pequeño (Edipo) para que lo matara, pero que él sintió compasión. Y Edipo, desolado, entiende que lo peor se ha cumplido (v. 1160-1185).

Como apuntábamos más arriba, la voz del Coro podría estar encarnando la intención ejemplarizante del poeta, recordándonos, a través de ella, cómo el más encumbrado de los hombres, ensalzado por su saber, y aclamado como rey, Edipo, ha caído en el más profundo abismo. Tal repentino y desgraciado cambio (peripéteia) -ingrediente esencial en la tragedia (Poética, 1452a-1452b)- servirá como ejemplo de que la voluntad humana -aun la del más poderoso y sabio-, no podrá remediar nuestra finitud: esa permanente exposición a la fortuna (Poética, 1452b-1453b), que nos hace tan vulnerables (Nussbaum, 1995, 27-50). Como colofón, y entre líneas, parece también sugerírsenos que en la vida nada es lo que parece:

\section{CORO.-}

Estrofa $1^{\mathrm{a}}$.

Ah, ¡descendencia de mortales! ¡Cómo considero que vivís una vida igual a nada! Pues, ¿qué hombre logra más felicidad que la que necesita para parecerlo y, una vez que ha dado esa impresión, para declinar? Teniendo este destino tuyo, el tuyo como ejemplo, ¡oh infortunado Edipo!, nada de los mortales tengo por dichoso.

Antístrofa $2^{\mathrm{a}}$.

Tú, que tras disparar el arco con incomparable destreza, conseguiste una dicha por completa afortunada, ;oh Zeus!, después de hacer perecer a la doncella de corvas garras cantora de enigmas, y te alzaste como un baluarte contra la muerte en mi tierra. Y por ello fuiste aclamado como mi rey y honrado con los mayores honores, mientras reinabas en la próspera Tebas.

Estrofa $2^{\mathrm{a}}$.

6 Sobre el desocultamiento dramático de la verdad como aletheia, haciéndose patente lo que estaba latente, Godoy (2016). No en vano, Aristóteles consideraba la anagnórisis de Edipo como la mejor (Aristóteles, Poética, 1455a18), y el proceso de reconocimiento (anagnórisis), de autocomprensión ocurrirá no sólo en el interior del drama, sino que también se involucra al espectador (Trueba, 2004, 106-107). 
$Y$ ahora, ¿de quién se puede oír decir que es más desgraciado? ¿Quién es el que vive entre violentas penas, quién entre padecimientos con su vida cambiada? (vv. 1190-1205).

El desastre se consuma. Un Mensajero anunciará los infortunios, queridos y no involuntarios (v. 1230) que azotan el palacio: el suicidio de Yocasta, sus palabras, llamando a gritos a Layo; el ir y venir de Edipo, fuera de sí, y cómo, ante la visión terrible de Yocasta, arrancará los dorados broches del vestido, golpeándose violentamente las cuencas de los ojos, y no una vez, sino muchas (v. 1275), "profiriendo expresiones impías, impronunciables para mí, como si se fuera a desterrar él mismo de esta tierra (...) Pronto podrás ver un espectáculo tal, como para mover a compasión, incluso al que le odiara”. (vv. 1290-1295).

Quedémonos, por el momento, con estos datos: la desesperación de Edipo, su violencia extrema contra sí mismo ${ }^{7}$; su desatada lengua; pero también, la referencia a la compasión, por haber caído en semejante estado, mostrando que el hombre, a pesar de su excelencia, de su inteligencia, de su voluntad y poder, es incapaz de tener todo bajo control: en eso radica nuestra finitud, y los dioses están ahí para recordárnoslo. El poeta lo plasmará apelando a la idea de que había un destino, trazado como castigo a Layo por desobedecer

7 Esto plantea el difícil problema de la hamartía, del error trágico (Dodds, 2007, 18-21; Gould, 2007, 59-67). Aristóteles no atribuye el error de Edipo a su maldad, sino que lo equipara sencillamente al que cometen otros que ostentan fama y poder (Poética, 1453a). Reputados intérpretes (Trueba, 2004, 110-116; Orsi, 2007, 319-321) siguen dicha interpretación: la hamartía no es una falla del carácter, sino fruto de la ignorancia (agnoía) de la situación. A nuestro juicio, sin negar la decisiva importancia de la agnoía, el error de Edipo sería múltiple: cree poder neutralizar los oráculos, el peso del destino; confía en su inteligencia y voluntad como infalibles, cuando el sujeto de conocimiento es limitado, y la voluntad humana no puede controlar todas las situaciones; pero, además, Edipo tiene una reacción muy violenta en el encuentro con el carromato real, que él, sorprendentemente, no identifica como tal, al no apartarse del camino, siendo entonces apartado por la fuerza. Edipo narró cómo al que lo echó fuera del camino lo golpeó movido por la cólera, y por ello se enfrentó al grupo, él sólo, hasta matarlos a todos. Y al anciano (Layo) lo sentenció de un solo golpe (vv. 806810). Este dato es muy significativo. También reacciona con hýbris al expresar su deseo de matar a Creonte (v. 620), su cuñado, tras discutir con él, porque piensa que ha urdido un complot en su contra. En modo alguno se muestra como alguien reflexivo, prudente, sino más bien colérico, altamente irascible. Tal arrebato de violencia se desata al final también contra sí mismo, al reventar sus ojos con los broches del vestido de Yocasta, acción, sin duda, terrible. El carácter del hombre es su destino, decía Heráclito (B,119) y hay manifiestamente una ira, una cólera incontrolada en el carácter de Edipo, que, a nuestro juicio, no podemos obviar sin forjarnos una idea dulcificada y falseada del personaje, sin pretender con ello una lectura moralizante del drama, que sería también discutible, como las interpretaciones meramente estética y fatalista (Dodds, 2007). Sófocles, en otras tragedias, ha sido muy crítico con tal desmesura (pensemos en el Áyax, respecto de Áyax, Agamenón y Menelao), y no iba a dejar de serlo ahora. Así que para nosotros, el error de Edipo es una amalgama de agnoía y de hýbris, que reflejan muy bien lo que somos: seres finitos, limitados en el saber y en el poder, y por lo mismo, seres fronterizos entre lo temible y la compasión, inmersos en un mundo objetivo, con su legalidad propia, contra la que nada puede nuestra voluntad, y que, además, no siempre podemos comprender (Dodds, 2007). Además, la acción es lo determinante en el drama trágico (Poética, 1449b-1450a). Ahora bien, a pesar de su hýbris, Edipo encarnaba cualidades admirables, heredadas de la épica homérica (Saravia, 2017), tales como el coraje, la inteligencia y la perseverancia. Ciertamente, superando el primer impulso suicida, hizo uso de su libertad al autolesionarse, pero también, y de un modo ejemplar, cuando buscó heroicamente la verdad sobre sí mismo, tal vez la única libertad asequible, aunque no por ello menos noble (Knox, 2007, 87-89). Y no en vano, ambos, el temor (phóbos) y la compasión (éleos) son los efectos (érgon) que tiene que producir el drama trágico (Poética, 1453b). 
un antiguo mandato divino, que nadie, ni los más poderosos (Layo, Edipo, Pólibo); ni los más despiadadas estrategias -como el infanticidio ideado por Layo y Yocasta-; ni la más penetrante inteligencia -como la de Edipo, descifrador de enigmas- podrá deshacer o burlar. Es la manera de interpretar que la voluntad humana choca con muros infranqueables. Si así no fuera, el hombre no sería un ser finito y digno de compasión (éleos), como Edipo, o cualquiera de nosotros. Edipo es paradigma de saber y de poder, ejemplo para todos, el mejor espejo donde mirarnos. Sófocles ha tenido que elegir, para que pensemos seriamente en ello, a quien entre todos parecía ser el más sabio y poderoso, pues, de otro modo, la finitud podría parecer sólo algo de los débiles. Y por eso ahora se descubrirá que detrás de todo está Apolo, dios de la luz, aunque Edipo sólo por su mano se ha cegado (v. 1330), haciéndose odioso a hombres y a dioses (v. 1380). La verdad, finalmente, resplandece, lo que nos parece otro de los mensajes esenciales del drama, aunque sea ocultada, silenciada, durante años. La voluntad humana también aquí tiene sus límites. Y por ello, cuando Creonte y Edipo vuelvan a encontrarse, y éste le pida que lo expulse de Tebas, Creonte le dirá que tiene que consultar antes al dios, y que ahora Edipo, mejor que nadie, estará en condiciones de creer en la divinidad (vv. 1420-1445). Y la reflexión final del Coro, con la que, reparemos en ello, se cierra la obra, nos podría estar sugiriendo la intención de la tragedia, tal y como venimos reclamando: que más allá de la lectura meramente política de Foucault, y a partir de su concepción simbólica de la verdad como conjunto de mitades, podríamos descubrir una perspectiva crítico-existencial sobre la futilidad de todo lo humano, encarnada en Edipo, paradigma de quien alcanzó lo más alto en la vida, aunque sólo por un breve tiempo:

CORIFEO. ¡Oh habitantes de mi patria, Tebas, mirad: he aquí a Edipo, el que solucionó los famosos enigmas y fue hombre poderosísimo; aquel al que los ciudadanos miraban con envidia por su destino! ¡En qué cúmulo de terribles desgracias ha venido a parar! De modo que ningún mortal puede considerar a nadie feliz con la mira puesta en el último día, hasta que llegue al término de su vida sin saber haber sufrido nada doloroso. (vv. 1525-1530).

\section{Conclusiones}

Somos Edipo y de un eterno modo la larga y triple bestia somos, todo lo que seremos y lo que hemos sido.

J.L. Borges. Edipo y el enigma.

Tras nuestro análisis, se pone de manifiesto la fertilidad hermenéutica foucaultiana: su concepción fragmentaria y simbólica de la verdad, y cómo los distintos puntos de vista, las distintas voces que confluyen en el drama -divinas y humanas- finalmente coinciden. Oportunamente, Foucault sugiere que los límites del saber autocrático de Edipo quedan al descubierto: sólo a través del testimonio de los otros -sobre todo de los menos poderososllega Edipo al verdadero conocimiento de sí mismo (Foucault, 2016, 70). Reveladora nos parece su lectura política de la obra, por cuanto la voluntad de preservar el poder acaba 
siendo determinante para la voluntad de verdad; aunque, a nuestro entender, lo será sólo hasta que irrumpa el relato de Yocasta sobre el planeado infanticidio, momento en el que la voluntad de verdad se hará prioritaria, arrastrando con ella no sólo a la voluntad de conservar el poder, sino al poder mismo. La polifonía de voces que intervienen y dialogan, en un intento de reconstruir fragmentos de la verdad, trasciende la mera perspectiva política del drama. Porque, aunque estemos, y no por casualidad, ante otra tragedia tebana ${ }^{8}$, Sófocles, a partir del cuestionamiento político y epistemológico del tirano (Orsi 2007, 301-323), podría estar adentrándonos en la complejidad de otros problemas: los límites del conocimiento; la naturaleza fragmentaria, aunque reconstruible, de la verdad; su necesario desvelamiento temporal y simbólico, cuyas mitades necesariamente tendrán que ensamblarse en un inexcusable juego de perspectivas; la humana finitud y fragilidad, de la que tampoco escapan los poderosos (Yocasta, Layo, Edipo), por más que orgullosamente confíen en su inteligencia o en su poder ${ }^{9}$ para someter a control una realidad siempre escurridiza, mostrándose su dramático desfondamiento; nuestra vulnerabilidad respecto a la humana felicidad, pues aquél que se las prometía más felices, por su exitoso saber y poder, aclamado y ensalzado por todos, acabará hundiéndose en el abismo de las mayores desgracias: Edipo, el mejor de todos (v. 9), será el culpable del míasma que está asolando la ciudad (v. 1378). Se nos dibuja, así, dramáticamente, la constitutiva ambigüedad del ser humano (deinos), fronterizo entre lo admirable y lo temible (Rocco, 2000, 62-63). Y la ironía trágica será el recurso dramático del que Sófocles se habría servido para plasmarlo genialmente en la obra, pues permite suspender la ficción y transitar reflexivamente a la realidad de cada cual (Orsi, 2007, 263-264).

Las últimas palabras del Coro -nunca mero espectador pasivo, sino verdadero actor, representando a la ciudad-, bien podrían encarnar la voz crítica del poeta, que se ha valido de la trayectoria ascendente -en saber y poder- de Edipo, hasta alcanzar el mayor de los éxitos, precisamente para ejemplarizar la fragilidad, la peripecia (peripéteia) a la que están expuestas las vidas humanas -incluso las de aquellos más poderosos- sugiriéndonos, finalmente, que además nada es lo que parece.

Todos somos, todos podemos ser Edipo. Por ello, asumiendo la propuesta de Foucault, aunque yendo un poco más allá, descubrimos también en Edipo Rey una no menos honda y zozobrante reflexión filosófica sobre la verdad, la vida y la condición humanas, cuyo potencial crítico es tal que no sólo supo inquietar a los conciudadanos atenienses de su tiempo, sino que, muchos siglos después, aún sigue haciéndolo con nosotros.

8 Aunque tenga muy presente la Atenas de Pericles (Knox, 1957, 105-107), no es casual el tema tebano: Tebas funciona como una anti-Atenas (Zeitlin, 1990); la hýbris es lo natural en el hombre tebano, encarnado en Edipo, que es, naturalmente, un tirano (Carrasco, 2009, 119-140). Para este contexto, Ahrensdorf (2009, 9-47). Sobre la interesante relación entre tragedia, puntos de vista y política, analizando el Filoctetes de Sófocles, Gallego (2012).

9 Aquí estriba fundamentalmente la hamartía de Edipo según Aristóteles (Poética, 1453a). 


\section{Referencias}

Ahrensdorf, P.J. (2009), Greek Tragedy and Political Philosophy. Rationalism and Religion in Sophocles' Theban Plays, Cambridge: Cambridge University Press.

Aristóteles, (1946), Poética, Edición bilingüe de García Bacca, México D.F.: Universidad Autónoma de México.

Carrasco, N. (2009), “Edipo Rey: entre lo político y lo sagrado", Ágora, 28/2, pp. 119-140.

Deleuze, G. (2014), Michel Foucault y el poder. Viajes iniciáticos I, Madrid: Errata naturae.

Dodds, E.R. (2007), "On Misunderstanding the Oedipus Rex", en: Bloom, H (ed.), Sophocles' Oedipus Rex, New York: Chelsea House books, pp. 17-29.

Errandonea, I. (1970), Sófocles y la personalidad de sus coros. Madrid: Moneda y Crédito.

Foucault, M. (2016), Del gobierno de los vivos, Curso del Collège de France (1979-1980), Madrid: Akal.

Foucault, M. (2015), Lecciones sobre la voluntad de saber. Curso del Collège de France (1970-1971). Seguido de El saber de Edipo (1972), Madrid: Akal.

Foucault, M. (2003), La verdad y las formas jurídicas, Barcelona: Gedisa, $2^{\mathrm{a}}$ ed.

Gallego, J. (2012), "La democracia ateniense en el desierto de Lemnos. El Filoctetes de Sófocles y la política del dêmos", en: Sancho, L., Iriarte, A. y Gallego, J. (comps.): Lógos y Arkhé. Discurso político y autoridad en la Grecia antigua, Buenos Aires: Miño y Dávila.

Gardiner, C.P. (1987), The Sophoclean Chorus. A Study of Character and Function, Iowa: University of Iowa Press.

Godoy, I. (2016), "La verdad como aletheia, un trágico asunto en Edipo Rey de Sófocles", Alpha, 0(42), pp. 163-176.

Gould, Th, (2007), "The Innocence of Oedipus: The Philosophers on Oedipus the King, Part III', en: Bloom, H (ed.), Sophocles' Oedipus Rex, New York: Chelsea House books, pp. 31-70.

Incerti, F. (2018), "Da ignorância ao conhecimiento: uma leitura foucaultiana de Édipo-Rei". Archai, $\mathrm{n}^{\circ}$ 23, May-Aug., pp. 109-133.

Kitto, H.D. (1968), Greek Tragedy. Fakenham: Methuen \&Coldt.

Knox, B. (2007), "Introduction to Oedipus the King”, en: Bloom, H (ed.), Sophocles' Oedipus Rex, New York: Chelsea House books, pp. 71-89.

Knox, B. (1957), Oedipus at Thebes, New Haven: Yale University Press.

Laleff, R. (2018), "La política en el secreto. Reflexiones a partir de lecturas contemporáneas de Edipo Rey", Araucaria, n 39, pp. 61-83.

Lariguet, G. (2014), "Tragedia y carácter moral. Comentarios a El saber del error. Filosofía y Tragedia en Sófocles de Rocío Orsi”, Discusiones, nº14, pp. 221-249.

Lasso de la Vega, J. (2003), Sófocles, Madrid: Ediciones clásicas.

Nussbaum, M. (1995), La fragilidad del bien, Madrid: Visor, La balsa de la medusa.

Monge, J. (2015), "El malestar en la ciudad: política de la verdad y tragedia en la lectura foucaultiana de Edipo Rey", Anacronismo e irrupción, vol. 5, nº 8, pp. 31-53.

Orsi, R. (2007), El saber del error. Filosofía y tragedia en Sófocles, Madrid: Plaza y Valdés Editores.

Rocco, Ch. (2000), Tragedia e Ilustración, Barcelona: Andrés Bello. 
Saravia, M.I. (2017), "La pervivencia de la épica homérica en Edipo Rey de Sófocles", Synthesis, vol. 24, $\mathrm{n}^{\circ} 1, \mathrm{e} 011$.

Sófocles (1986), Tragedias, Madrid: Biblioteca Clásica de Gredos, ed. Assela Alamillo, introducción de J.S. Lasso de la Vega.

Steiner, G. (2012), La muerte de la tragedia, Madrid: F.C.E., Ediciones Siruela.

Trueba, C. (2004), Ética y tragedia en Aristóteles, Barcelona: Anthropos.

Vernant, J.P., Vidal-Naquet, P. (1987), Mito y Tragedia en la Grecia antigua I, Madrid: Taurus.

Williams, B. (2011), Vergüenza y necesidad, Madrid: La balsa de la medusa.

Zeitlin, F. (1990), "Thebes: Theater of Self and Society in Athenian Drama", en: Winkler, J., Zeitlin, F., (eds.): Nothing to do with Dionisos? Princeton: Princeton University Press, pp. 130-167. 
